\title{
Motor Exit Point (MEP) Glia: Novel Myelinating Glia That Bridge CNS and PNS Myelin
}

\author{
Laura Fontenas and Sarah Kucenas* \\ Department of Biology, University of Virginia, Charlottesville, VA, United States
}

Oligodendrocytes (OLs) and Schwann cells (SCs) have traditionally been thought of as the exclusive myelinating glial cells of the central and peripheral nervous systems (CNS and PNS), respectively, for a little over a century. However, recent studies demonstrate the existence of a novel, centrally-derived peripheral glial population called motor exit point (MEP) glia, which myelinate spinal motor root axons in the periphery. Until recently, the boundaries that exist between the CNS and PNS, and the cells permitted to cross them, were mostly described based on fixed histological collections and static lineage tracing. Recent work in zebrafish using in vivo, time-lapse imaging has shed light on glial cell interactions at the MEP transition zone and reveals a more complex picture of myelination both centrally and peripherally.

Keywords: myelin, oligodendrocyte, schwann cell, motor exit point glia, zebrafish, boundary cap cell

OPEN ACCESS

Edited by:

Keith Murai,

McGill University, Canada

Reviewed by:

Vanessa Auld,

University of British Columbia,

Canada

Alexandre Leite Rodrigues Oliveira, Universidade Estadual de Campinas,

Brazil

Maria Elena De Bellard, California State University, Northridge, United States

${ }^{*}$ Correspondence:

Sarah Kucenas sk4ub@virginia.edu

Received: 10 June 2018 Accepted: 11 September 2018 Published: 02 October 2018

Citation:

Fontenas $L$ and Kucenas $S$ (2018) Motor Exit Point (MEP) Glia: Novel Myelinating Glia That Bridge

CNS and PNS Myelin.

Front. Cell. Neurosci. 12:333. doi: 10.3389/fncel.2018.00333

\section{INTRODUCTION}

Myelin is a unique plasma membrane extension produced by specialized glial cells that is wrapped around axons and facilitates rapid transmission of electrical impulses over long distances. Although myelin appeared 430 million years ago in the vertebrate lineage (Gould et al., 2008; Zalc, 2016), continuous efforts from various fields of biology are still unraveling the many mysteries of myelin and myelin producing cells.

The nervous system is a complex organ whose function depends on the precise organization of its components. The central nervous system (CNS) consists of the brain and the spinal cord, while the peripheral nervous system (PNS) consists of neural tissue outside of the CNS, including motor and sensory axons and sensory neurons clustered in ganglia. While many neurons establish circuits within the CNS, some of these cells send their axons (e.g., motor axons) freely across specialized CNS boundaries known as transition zones (TZs) and travel long distances throughout the organism and ultimately make synapses on peripheral tissues, including muscle. By associating tightly with axons to ultimately ensheath and insulate them with fatty membranes called myelin, myelinating cells increase nerve impulse conduction speed and strengthen the function and efficiency of the whole nervous system.

In the CNS, oligodendrocytes (OLs), which are derived from neural tube precursors, make myelin in the brain and spinal cord, while Schwann cells (SCs), which originate from the neural crest (NC), myelinate axons of the PNS (Jessen and Mirsky, 2005; Bergles and Richardson, 2015).

\footnotetext{
Abbreviations: BC, boundary cap; CNS, central nervous system; dpf, day post-fertilization; DREZ, dorsal root entry zone; DRG, dorsal root ganglion; eGFP, enhanced green fluorescent protein; Gpr126, G-protein coupled receptor 126; hpf, hour post-fertilization; MBP, myelin basic protein; MEP, motor exit point; MN, motor neuron; NC, neural crest; OL, oligodendrocyte; OPC, oligodendrocyte progenitor cell; PNS, peripheral nervous system; SC, Schwann cell; TZ, transition zone; Wif1, Wnt-inhibitory factor 1.
} 
In addition to expressing different sets of genes, central and peripheral glia also ensheath axons in myelin in distinct ways. OLs expand multiple membrane processes, which wrap several axonal segments that often belong to different neurons, while a single SC ensheaths a single axonal segment. Although OLs and SCs myelinate axons in mechanistically distinct ways, their territories come into close proximity along common axons at motor exit point (MEP) TZs, where they are separated by only a few microns (Fraher and Kaar, 1984; Fraher, 2002).

The mammalian CNS/PNS boundary is delineated by a thick layer of astrocytic endfeet that is continuous with the glia limitans which covers the surface of the spinal cord with the exception of perforations that allow axons to cross (reviewed in Fontenas and Kucenas, 2017). Ultrastructural studies show that central and peripheral glial cells, namely OLs and SCs, are present near the MEP TZ, but are never seen intermixing. In fact, MEP TZs are described as an abrupt transition between central and peripheral glia (Doucette, 1991; Franklin and Blakemore, 1993; Fraher et al., 2007). However, intriguingly, using in vivo imaging in zebrafish, we and others observe the presence of continuous $m b p^{+}$myelin internodes along motor axons crossing the MEP TZ (Figure 1C; Monk et al., 2009; Almeida et al., 2011; Auer et al., 2018).

The two distinct yet connected halves of the nervous system have their own, non-overlapping myelin forming cells and myelin sheaths. Does this mean myelinating glia cannot function in the half where they do not originate? What keeps them segregated in the developing and mature nervous system? How does unique myelin on either side of the CNS/PNS TZ result in an efficiently insulated nerve?

Work from our lab and others demonstrates the presence of additional glial cells outside the spinal cord at the TZ between the CNS and the PNS, which function to segregate central and peripheral components from ectopically crossing this boundary (Vermeren et al., 2003; Kucenas et al., 2009; Coulpier et al., 2010; Smith et al., 2014). While most studies previously focused on nervous system TZs using histological and ultrastructural methods, recent studies using in vivo, time-lapse imaging in zebrafish have shed light on these dynamic structures and revealed novel glial cell populations that cross these TZs (Kucenas et al., 2008, 2009; Smith et al., 2014; Welsh and Kucenas, 2018).

In this article, we will provide a short review on MEP glia, a recently discovered population of centrally-derived glial cells that myelinate spinal motor nerve root axons and compare them to traditional myelinating glial populations in both form and function.

\section{MEP GLIA ARE CENTRALLY-DERIVED PERIPHERAL MYELINATING CELLS}

Until recently, the TZs between the CNS and the PNS were thought to be selectively permeable to axons either entering or exiting the spinal cord, while the establishment and maintenance of the territories occupied by glial cells remained poorly described and understood. However, recent studies demonstrate that MEP TZs are occupied by highly dynamic cell populations and are precisely regulated over the course of nervous system development. While OL lineage cells and SCs segregate and function in the CNS and PNS, respectively, other glial cell populations freely cross the MEP $\mathrm{TZ}$ as spinal motor nerves are being formed (Kucenas et al., 2008, 2009; Smith et al., 2014, 2016; Fontenas and Kucenas, 2017).

One of these cell populations, MEP glia, originate from pMN domain precursors in the ventral neural tube, which also give rise to motor neurons (MNs) and OL lineage cells. After exiting the CNS, MEP glia reside just outside of the ventral spinal cord along spinal motor nerve root axons, occupying axonal territory between SCs in the periphery and OLs in the spinal cord. The pMN domain constitutes the major site of expression of the basic helix-loop-helix (bHLH) transcription factor Olig2. In zebrafish, olig2 $^{+}$precursors first produce MNs and then switch to generate glial cells at approximately 36 hours post fertilization (hpf; Smith et al., 2014; Ravanelli and Appel, 2015). MEP glia exit the ventral spinal cord through the MEP TZ at around $50 \mathrm{hpf}$, before the onset of oligodendrocyte progenitor cell (OPC) migration, and then divide to populate the motor root.

MEP glia and OL lineage cells share a common progenitor and as a consequence, the two myelinating cell populations-although they function in two distinct halves of the nervous system-share common markers. MEP glia express olig2 (Figures 1 A,B), whose expression is progressively turned off after MEP glia reach the motor nerve root, prior to motor axon myelination (Smith et al., 2014). Both central and peripheral myelinating glial cells in zebrafish as well as in mammals, express the transcription factor Sox10 (Figure 1B). Numerous studies show that sox10 is required for NC cell development, including SCs, as well as for OL lineage differentiation and promotes myelin gene expression (Kelsh and Eisen, 2000; Dutton et al., 2001; Gilmour et al., 2002; Kucenas et al., 2009; Takada et al., 2010). Unsurprisingly, MEP glia also express and require sox10 for their development and function (Kucenas et al., 2009; Smith et al., 2014). In vivo, time-lapse imaging has recently revealed sox10 expression in MEP glia before they even exit the spinal cord and is maintained throughout their development and differentiation. The pioneer study demonstrating the existence of centrally-derived glial cells at the MEP TZ, shows that zebrafish colorless $(\mathrm{cls})$ mutants, which harbor a mutation in sox10 and lack SCs, have peripheral OPCs that differentiate and myelinate spinal motor nerves, suggesting that sox10 may be required for MEP glial function or survival (Kucenas et al., 2009).

Intriguingly, MEP glia not only express the transcription factors sox10 and olig2, which together are a combination that is characteristic of CNS myelinating glia, they also express foxd3 (Figures 1A,B), a transcription factor present in all NC cells including sox $10^{+}$peripheral glia such as SCs in zebrafish (Odenthal and Nüsslein-Volhard, 1998; Gilmour et al., 2002; Hochgreb-Hägele and Bronner, 2013; Smith et al., 2014). Using in vivo, time-lapse imaging and the Gt(foxd3:mcherry) transgenic line that faithfully mimics the endogenous expression of foxd3 (Hochgreb-Hägele and Bronner, 2013), foxd3 expression was observed as early as $46 \mathrm{hpf}$, before MEP glia exit the spinal cord, and persisted in these cells as late as 8 day 


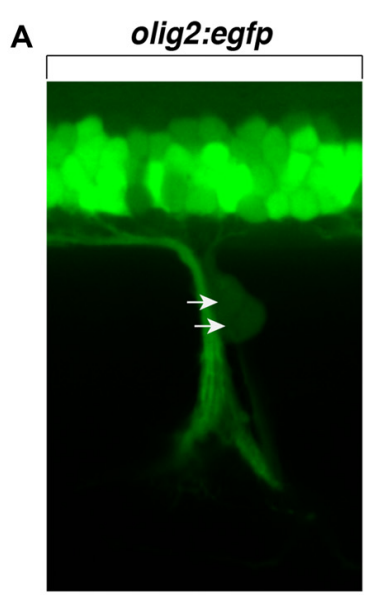

B

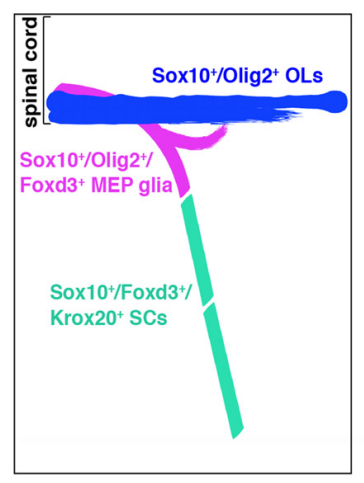

D

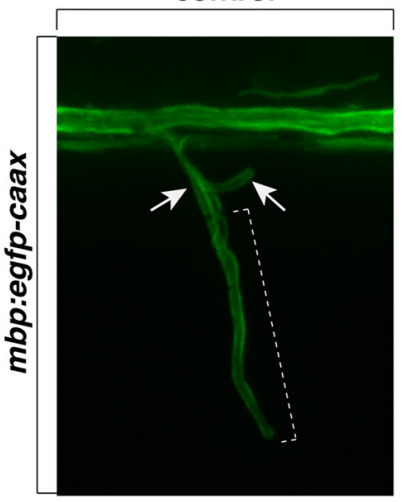

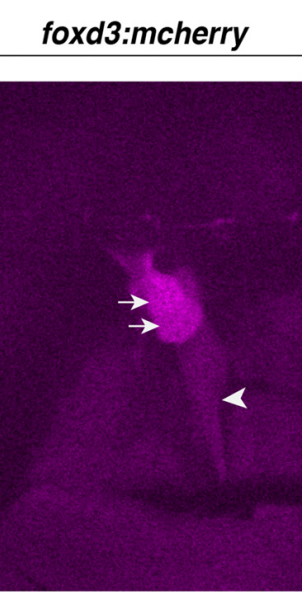

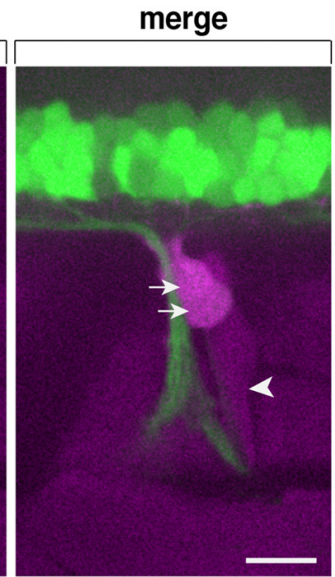

C

mbp:egfp-caax

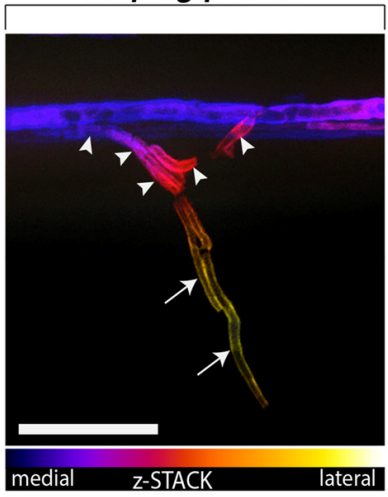

gpr126

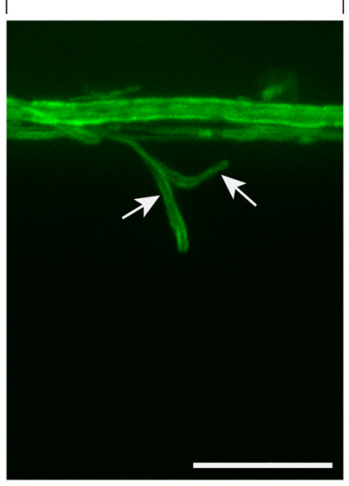

E

control

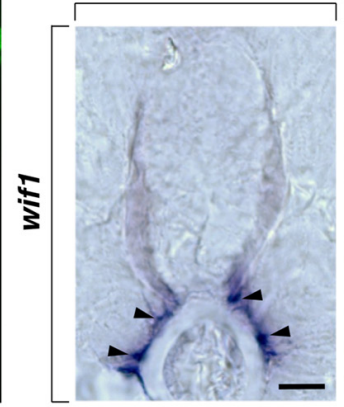

gpr126\%

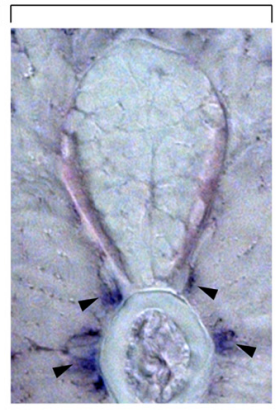

FIGURE 1 | Centrally-derived motor exit point (MEP) glia myelinate motor nerve roots. (A) Lateral view of a olig2:egfp;foxd3:mcherry zebrafish trunk showing olig2+/foxd3+ MEP glia (arrows) and olig2-/foxd3+ SCs (arrowheads) along a motor nerve at 55 hour post-fertilization (hpf). (B) Diagram representing central and peripheral myelinating glial markers. (C) Pseudo-colored z-stack of a lateral view of a mbp:egfp-caax trunk at 5 day post-fertilization (dpf). MEP glial myelin sheaths (arrowheads) originate within the spinal cord and project laterally along motor nerve axons, coming close to schwann cells (SC) myelin (arrows). (D) SC myelin (bracket) but not MEP glial myelin (arrows) is absent in G-protein coupled receptor 126 (gpr126) mutants at 5 days post fertilization (dpf). (E) In situ hybridization showing the presence of Wnt-inhibitory factor 1 (wif1+) MEP glia (arrowheads) along motor nerve roots in 3 dpf control and gpr126 mutant larvae. Scale bar, (A-D) $50 \mu \mathrm{m}$, (E) $20 \mu \mathrm{m}$.

post-fertilization (dpf; Smith et al., 2014). Despite the fact that they express the peripheral marker foxd3, MEP glia do not express krox20 (also known as early growth response protein 2-egr 2 b), a transcription factor expressed by boundary cap (BC) cells that is also required for SC myelination (data not shown; Wilkinson et al., 1989; Topilko et al., 1994; Monk et al., 2009; Coulpier et al., 2010; Smith et al., 2014).

In chick and mouse, $\mathrm{BC}$ cells are traditionally described as NC derivatives that migrate along the ventral path and 
transiently reside in clusters at dorsal root entry zone (DREZ) and MEP TZs, where axons enter and exit the spinal cord, respectively (Niederländer and Lumsden, 1996; Golding and Cohen, 1997; Vermeren et al., 2003). BC cells eventually give rise to neuronal and glial cell populations, including myelinating SCs (Maro et al., 2004; Gresset et al., 2015; Radomska and Topilko, 2017). At the MEP, BC cells function to constrain $\mathrm{MN}$ cell bodies to the spinal cord, as their ablation leads to ectopic MNs along motor nerve roots (Vermeren et al., 2003; Bron et al., 2007). The Topilko laboratory also demonstrated that upon Krox20 inactivation, which results in the absence of both SCs and BC cells, OL ectopically populate the ventral and dorsal roots (Coulpier et al., 2010).

To date, BC cells have not been described in zebrafish, however, MEP glia do express the BC cell marker Wnt-inhibitory factor 1 (wif1; Figure 1E), which no other myelinating cells express (Coulpier et al., 2009; Smith et al., 2014). Taken together, MEP glia express a subset of both central and peripheral glial markers (sox10, olig2, foxd3 and wif1) that are not found all together in any other myelinating glial cell type (Figure 1B). Although MEP glia originate in the CNS and function in the PNS, their identity is not truly that of either a central or a peripheral glial cell, but rather appear to be a hybrid glial cell.

Previous work from our lab shows that MEP glia differentiate into myelinating glia and by $3 \mathrm{dpf}$, start to ensheath the proximal portion of spinal motor nerve axons, also known as motor nerve roots (Figures 1C,D; Smith et al., 2014). In the same initial study, we demonstrate that MEP glia restrict OPCs to the spinal cord through contact-mediated repulsion. Using in vivo, time-lapse imaging, we describe that prior to $3 \mathrm{dpf}$, OPCs extend membrane processes into the periphery to sense the environment. Immediately upon contact with a MEP glial cell, OPCs retract their processes from the periphery and pursue their migration within the spinal cord. Under normal physiological conditions, OPC cell bodies are never found outside of the spinal cord but invade peripheral nerves in the absence of MEP glia (Kucenas et al., 2009; Smith et al., 2014). Consistent with these findings, OPCs exit the spinal cord through MEP TZs in mutants lacking all peripheral myelinating glia (Smith et al., 2014). For example, OPCs are found along peripheral nerves in erbb3b mutants that harbor a mutation in the receptor tyrosine kinase, erbb3b and lack all peripheral myelinating glia (Lyons et al., 2005; Smith et al., 2014; Morris et al., 2017). Additionally, using in vivo, time-lapse imaging coupled with single cell ablation using a nitrogen-pulsed laser, our lab showed that specific ablation of MEP glia leads to the ectopic exit of OPCs from the spinal cord (Smith et al., 2014). However, OPCs are never found in the PNS when regions surrounding MEP glia are ablated or when radial glia, another glial cell population present at the MEP TZ, are genetically ablated (Smith et al., 2014, 2016). These observations demonstrate that MEP glia contribute to a selective gating mechanism at MEP TZs. Direct interactions between myelinating glial cells from the CNS and PNS participate in regulating glial migration across TZs and contribute to the establishment and maintenance of the
CNS/PNS boundary and continuous myelination along spinal motor axons.

\section{ELUCIDATING THE MOLECULAR MECHANISMS THAT MEDIATE MEP GLIAL DEVELOPMENT AND FUNCTION}

Although myelin promotes the rapid propagation of electrical activity, not all axons are myelinated. In the PNS, studies unanimously point to a straightforward mechanism, whereby axonal caliber determines whether or not myelination will occur and also determines the extent of myelin produced (Taveggia et al., 2005; Newbern and Birchmeier, 2010; Perlin et al., 2011). On the other hand, central myelination is a divisive topic, and although we still understand only a little about how neuronal activity influences OL myelination, coupling neuronal activity to myelination arouses interest and has become a rapidly growing field. Elegant work from the Chan laboratory demonstrates that OLs can myelinate electrically silent nanofibers in vitro (Lee et al., 2012). However, there are other studies that demonstrate that environmental experience and neuronal activity in vivo are essential for myelination. Evidence from studies using in vitro models, in vivo, time-lapse imaging in zebrafish, and also mouse models suggest that OL lineage cells can detect and respond to extrinsic cues during their development and differentiation, but the source and identity of these signals are matter of debate (Kirby et al., 2006; Hines et al., 2015; Mensch et al., 2015; Etxeberria et al., 2016; Koudelka et al., 2016; see; Almeida and Lyons, 2017; Welsh and Kucenas, 2018 for recent reviews).

MEP glia ensheath and myelinate motor axon segments that do not overlap with myelin internodes made by SCs found further distally along the nerve. In fact, the boundary between MEP glial and SC myelin sheaths is clearly delineated by a node of Ranvier (Figures 2A,B). Like the well described and century-old myelinating glial cells SCs and OLs, MEP glia have the ability to cluster sodium channels to nodes of Ranvier as they initiate axonal wrapping, thus promoting saltatory conduction from the very proximal portion of motor nerve root axons (Figures 2A-C; Voas et al., 2009). MEP glial myelin internodes are flanked by nodes of Ranvier inside the spinal cord and just peripheral to the MEP TZ (Figures 2A-C). MEP glia also express myelin basic protein $(m b p)$ and both $m b p$ and transcript and MBP protein can be detected along motor nerve root axons as early as $4 \mathrm{dpf}$ (Figures 2B,C; Brösamle and Halpern, 2002; Smith et al., 2014).

Fascinatingly, in G protein-coupled receptor 126 (gpr126) mutants, where SCs are arrested at the pro-myelinating stage and fail to myelinate peripheral axons, Monk et al. (2009) described the presence of myelin along spinal motor root axons, reminiscent of projections of central myelin through MEP TZs. At the time, MEP glia were yet to be discovered and characterized. Therefore, projections of central myelin were the most plausible explanation for such a phenotype. However, recent work from our lab has extended these findings and we now know that the projections of "central myelin" into the periphery observed in gpr126 mutants are, in fact, 

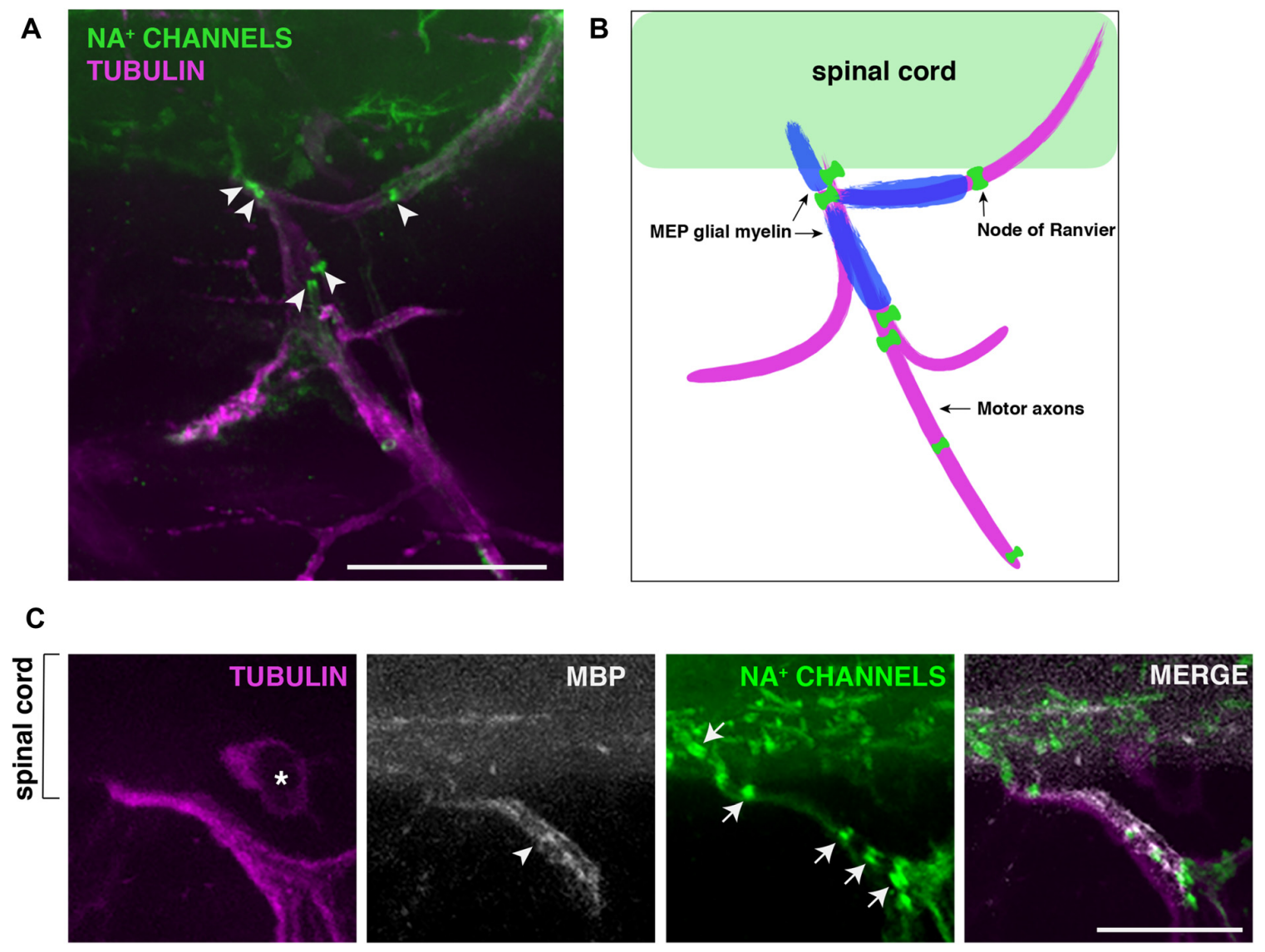

D

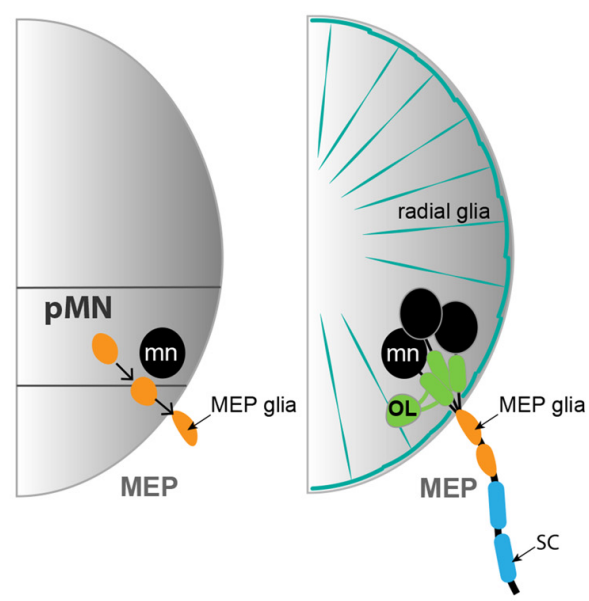

E

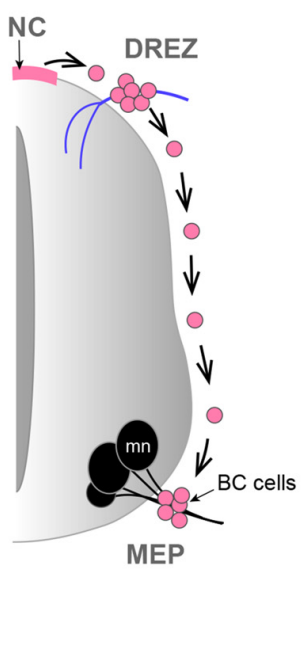

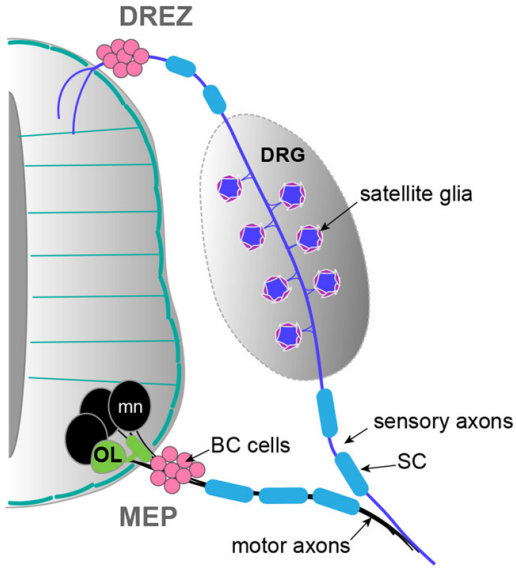

FIGURE 2 | MEP glial myelin is flanked by nodes of ranvier. (A) Lateral view of a 5 dpf zebrafish trunk stained with antibodies specific to pan $\mathrm{Na}^{+}$channels (clone $\mathrm{k} 58 / 35$ ) and acetylated tubulin shows that MEP glial territory is flanked by sodium channels clustered in Nodes of Ranvier (arrowheads) along motor nerve roots. (B) Diagram showing MBP+ MEP glial myelin (blue) delineated by nodes of Ranvier (green) along motor nerve root axons (magenta). (C) Immunostaining showing $\mathrm{MBP}^{+}$MEP glial myelin (arrowhead) and nodes of Ranvier (arrows) along motor nerve root axons (magenta). Asterisks point to dorsal root ganglion (DRG).

(D) Schematic of zebrafish MEP transition zones (TZs) and the diverse populations of glial cells orchestrating the CNS/PNS boundary. CNS-derived MEP glia (orange) that reside along motor neuron ( $\mathrm{mn}$; black) axons restrict the oligodendrocyte lineage (OL; green) to the spinal cord. Radial glia (teal green) cover the surface of the spinal cord and prevent peripheral glia such as MEP glia and SC (blue) from entering the CNS. (E) Schematic of a mammalian neural tube showing neural crest (NC)-derived boundary cap (BC) cells (pink) sitting at the dorsal root entry zone (DREZ) and MEP TZs. BC cells prevent mn (black) cell bodies from transgressing the spinal cord boundary. Scale bar, (A) $50 \mu \mathrm{m}$, (C) $25 \mu \mathrm{m}$. 
MEP glial myelin sheaths (Figures 1D,E). These data therefore demonstrate that, unlike SCs, MEP glia do not require gpr126 to initiate myelination. And as previously mentioned, these glial cells also do not express Krox20. Therefore, they are a CNS-derived, peripheral glial cell that myelinates peripheral axons, but uses a distinct molecular mechanism to initiate myelination.

\section{ARE MEP GLIA THE ONLY CENTRALLY-DERIVED PERIPHERAL GLIA?}

For years, mammalian BC cells were thought to constrain MN cell bodies to the spinal cord by repulsion from outside the spinal cord (Bron et al., 2007; Mauti et al., 2007; Chauvet and Rougon, 2008; Bravo-Ambrosio and Kaprielian, 2011; Garrett et al., 2016). However, how this physically worked was unclear, as neither BC cells or $\mathrm{MN}$ cell bodies were close enough to physically interact to mediate the repulsion (Figure 2E). Intriguingly, a recent review from the Topilko laboratory revealed a new piece of data that shows that $\mathrm{Krox}_{2} \mathrm{O}^{+} \mathrm{BC}$ cells project membrane processes across the MEP TZ into the ventral spinal cord (Radomska and Topilko, 2017). These recent data are consistent with our longstanding hypothesis that $\mathrm{BC}$ cells might be a diverse cell population and include a subpopulation of centrally-derived cells, analogous to zebrafish MEP glia (Figure 2D). Consistent with this hypothesis, a recent study demonstrates that in a demyelination context, Olig2 ${ }^{+}$cells residing within the mouse spinal cord give rise to SCs, which are usually NC-derived (Zawadzka et al., 2010). Is this phenomenon a response to demyelination, or does it also exist under normal circumstances? Previous studies describe the identification of perineurial glia, the glial cells that form the perineurium found around peripheral motor nerves, and demonstrate that they are CNS-derived in Drosophila, zebrafish and mouse (Sepp et al., 2001; Kucenas et al., 2008; Clark et al., 2014; Kucenas, 2015). However, the origin of perineurial glia was of intense debate for decades as they were previously thought to be fibroblasts. Could this model of CNS-derived peripheral glia apply to other cell types? Understanding the diversity of origin for glial cells and their ability to be specified in one region of the nervous system but function in another, could provide insight into cell interaction, segregation and selective gating mechanisms.

\section{REFERENCES}

Almeida, R. G., Czopka, T., Ffrench-Constant, C., and Lyons, D. A. (2011). Individual axons regulate the myelinating potential of single oligodendrocytes in vivo. Development 138, 4443-4450. doi: 10.1242/dev. 071001

Almeida, R. G., and Lyons, D. A. (2017). On myelinated axon plasticity and neuronal circuit formation and function. J. Neurosci. 37, 10023-10034. doi: 10.1523/JNEUROSCI.3185-16.2017

Auer, F., Vagionitis, S., and Czopka, T. (2018). Evidence for myelin sheath remodeling in the CNS revealed by in vivo imaging. Curr. Biol. 28, 549-559. doi: 10.1016/j.cub.2018.01.017

Bergles, D. E., and Richardson, W. D. (2015). Oligodendrocyte development and plasticity. Cold Spring Harb. Perspect. Biol. 8:a020453. doi: 10.1101/cshperspect. a020453

\section{CONCLUSION}

MEP glial development and function raise many new questions. What are the signals mediating OPC-MEP glial interactions across the MEP TZ? Do MEP glia also interact with SCs and via which molecular mechanisms? Does this novel, centrally-derived glial cell population adopt a central-like myelination pattern, involving the extension of multiple membrane processes to wrap more than one axonal segment? Or does it behave more like a Schwann cell, ensheathing a single axonal segment in a truly peripheral-like fashion? Or alternatively, is MEP glial myelin a kind of hybrid myelin featuring both central and peripheral characteristics? How do MEP glia myelinate if they do not require Krox20 or Gpr126? Electron microscopy of the MEP TZ will be needed to examine MEP glial development at the ultrastructural level to characterize their myelin sheaths that connect the CNS and PNS. RNA-sequencing coupled to genome editing tools such as CRISPR/Cas9 will shed light on the molecular mechanisms that drive MEP glial development, their gating function and differentiation into peripheral myelinating glia. Recent studies in zebrafish have uncovered the existence of novel centrallyderived myelinating glia that function in the PNS and are required for nervous system TZ integrity, and future work may change our way of thinking about mammalian myelinating glia as well.

\section{AUTHOR CONTRIBUTIONS}

LF wrote the manuscript with input from SK.

\section{FUNDING}

This work was supported by grants from the NIH/National Institute of Neurological Disorders and Stroke (NINDS; R01NS072212 and R21NS092070), The Hartwell Foundation and The Owens Family Foundation.

\section{ACKNOWLEDGMENTS}

We thank Maria Ali and Andrew Latimer for their helpful comments on the manuscript.

Bravo-Ambrosio, A., and Kaprielian, Z. (2011). Crossing the border: molecular control of motor axon exit. Int. J. Mol. Sci. 12, 8539-8561. doi: 10.3390/ijms12128539

Bron, R., Vermeren, M., Kokot, N., Andrews, W., Little, G. E., Mitchell, K. J., et al. (2007). Boundary cap cells constrain spinal motor neuron somal migration at motor exit points by a semaphorin-plexin mechanism. Neural Dev. 2:21. doi: 10.1186/1749-8104-2-21

Brösamle, C., and Halpern, M. E. (2002). Characterization of myelination in the developing zebrafish. Glia 39, 47-57. doi: 10.1002/glia.10088

Chauvet, S., and Rougon, G. (2008). Semaphorins deployed to repel cell migrants at spinal cord borders. J. Biol. 7:4. doi: 10.1186/jbiol65

Clark, J. K., O’keefe, A., Mastracci, T. L., Sussel, L., Matise, M. P., and Kucenas, S. (2014). Mammalian $N k x 2.2^{+}$perineurial glia are essential for motor nerve development. Dev. Dyn. 243, 1116-1129. doi: 10.1002/dvdy. 24158 
Coulpier, F., Decker, L., Funalot, B., Vallat, J.-M., Garcia-Bragado, F., Charnay, P., et al. (2010). CNS/PNS boundary transgression by central glia in the absence of Schwann cells or Krox20/Egr2 function. J. Neurosci. 30, 5958-5967. doi: 10.1523/JNEUROSCI.0017-10.2010

Coulpier, F., Le Crom, S., Maro, G. S., Manent, J., Giovannini, M., Maciorowski, Z., et al. (2009). Novel features of boundary cap cells revealed by the analysis of newly identified molecular markers. Glia 57, 1450-1457. doi: 10.1002/glia. 20862

Doucette, R. (1991). PNS-CNS transitional zone of the first cranial nerve. J. Comp. Neurol. 312, 451-466. doi: 10.1002/cne.903120311

Dutton, K. A., Pauliny, A., Lopes, S. S., Elworthy, S., Carney, T. J., Rauch, J., et al. (2001). Zebrafish colourless encodes sox10 and specifies non-ectomesenchymal neural crest fates. Development 128, 4113-4125.

Etxeberria, A., Hokanson, K. C., Dao, D. Q., Mayoral, S. R., Mei, F., Redmond, S. A., et al. (2016). Dynamic modulation of myelination in response to visual stimuli alters optic nerve conduction velocity. J. Neurosci. 36, 6937-6948. doi: 10.1523/JNEUROSCI.0908-16.2016

Fontenas, L., and Kucenas, S. (2017). Livin' on the edge: glia shape nervous system transition zones. Curr. Opin. Neurobiol. 47, 44-51. doi: 10.1016/j.conb.2017. 09.008

Fraher, J. P. (2002). Axons and glial interfaces: ultrastructural studies*. J. Anat. 200, 415-430. doi: 10.1046/j.1469-7580.2002.00037.x

Fraher, J. P., Dockery, P., O’Donoghue, O., Riedewald, B., and O’leary, D. (2007). Initial motor axon outgrowth from the developing central nervous system. J. Anat. 211, 600-611. doi: 10.1111/j.1469-7580.2007.00807.x

Fraher, J. P., and Kaar, G. F. (1984). The transitional node of ranvier at the junction of the central and peripheral nervous systems: an ultrastructural-study of its development and mature form. J. Anat. 139, 215-238.

Franklin, R. J. M., and Blakemore, W. F. (1993). Requirements for Schwann-cell migration within cns environments: a viewpoint. Int. J. Dev. Neurosci. 11, 641-649. doi: 10.1016/0736-5748(93)90052-f

Garrett, A. M., Jucius, T. J., Sigaud, L. P. R., Tang, F.-L., Xiong, W.-C., Ackerman, S. L., et al. (2016). Analysis of expression pattern and genetic deletion of Netrin5 in the developing mouse. Front. Mol. Neurosci. 9:3. doi: $10.3389 /$ fnmol.2016.00003

Gilmour, D. T., Maischein, H.-M., and Nüsslein-Volhard, C. (2002). Migration and function of a glial subtype in the vertebrate peripheral nervous system. Neuron 34, 577-588. doi: 10.1016/s0896-6273(02)00683-9

Golding, J. P., and Cohen, J. (1997). Border controls at the mammalian spinal cord: late-surviving neural crest boundary cap cells at dorsal root entry sites may regulate sensory afferent ingrowth and entry zone morphogenesis. Mol. Cell. Neurosci. 9, 381-396. doi: 10.1006/mcne.1997.0647

Gould, R. M., Oakley, T., Goldstone, J. V., Dugas, J. C., Brady, S. T., and Gow, A. (2008). Myelin sheaths are formed with proteins that originated in vertebrate lineages. Neuron Glia Biol. 4, 137-152. doi: 10.1017/S1740925x09990238

Gresset, A., Coulpier, F., Gerschenfeld, G., Jourdon, A., Matesic, G., Richard, L., et al. (2015). Boundary caps give rise to neurogenic stem cells and terminal glia in the skin. Stem Cell Reports 5, 278-290. doi: 10.1016/j.stemcr.2015. 06.005

Hines, J. H., Ravanelli, A. M., Schwindt, R., Scott, E. K., and Appel, B. (2015). Neuronal activity biases axon selection for myelination in vivo. Nat. Neurosci. 18, 683-689. doi: 10.1038/nn.3992

Hochgreb-Hägele, T., and Bronner, M. E. (2013). A novel FoxD3 gene trap line reveals neural crest precursor movement and a role for FoxD3 in their specification. Dev. Biol. 374, 1-11. doi: 10.1016/j.ydbio.2012.11.035

Jessen, K. R., and Mirsky, R. (2005). The origin and development of glial cells in peripheral nerves. Nat. Rev. Neurosci. 6, 671-682. doi: 10.1038/nrn1746

Kelsh, R. N., and Eisen, J. S. (2000). The zebrafish colourless gene regulates development of non-ectomesenchymal neural crest derivatives. Development $127,515-525$.

Kirby, B. B., Takada, N., Latimer, A. J., Shin, J., Carney, T. J., Kelsh, R. N., et al. (2006). In vivo time-lapse imaging shows dynamic oligodendrocyte progenitor behavior during zebrafish development. Nat. Neurosci. 9, 1506-1511. doi: 10.1038/nn1803

Koudelka, S., Voas, M. G., Almeida, R. G., Baraban, M., Soetaert, J., Meyer, M. P., et al. (2016). Individual neuronal subtypes exhibit diversity in CNS myelination mediated by synaptic vesicle release. Curr. Biol. 26, 1447-1455. doi: 10.1016/j. cub.2016.03.070
Kucenas, S. (2015). Perineurial glia. Cold Spring Harb. Perspect. Biol. 7:a020511. doi: 10.1101/cshperspect.a020511

Kucenas, S., Takada, N., Park, H. C., Woodruff, E., Broadie, K., and Appel, B. (2008). CNS-derived glia ensheath peripheral nerves and mediate motor root development. Nat. Neurosci. 11, 143-151. doi: 10.1038/nn2025

Kucenas, S., Wang, W. D., Knapik, E. W., and Appel, B. (2009). A selective glial barrier at motor axon exit points prevents oligodendrocyte migration from the spinal cord. J. Neurosci. 29, 15187-15194. doi: 10.1523/JNEUROSCI.419309.2009

Lee, S., Leach, M. K., Redmond, S. A., Chong, S. Y., Mellon, S. H., Tuck, S. J., et al. (2012). A culture system to study oligodendrocyte myelination processes using engineered nanofibers. Nat. Methods 9, 917-922. doi: 10.1038/nmeth.2105

Lyons, D. A., Pogoda, H.-M., Voas, M. G., Woods, I. G., Diamond, B., Nix, R., et al. (2005). erbb3 and erbb2 are essential for schwann cell migration and myelination in zebrafish. Curr. Biol. 15, 513-524. doi: 10.1016/j.cub.2005. 02.030

Maro, G. S., Vermeren, M., Voiculescu, O., Melton, L., Cohen, J., Charnay, P., et al. (2004). Neural crest boundary cap cells constitute a source of neuronal and glial cells of the PNS. Nat. Neurosci. 7, 930-938. doi: 10.1038/nn1299

Mauti, O., Domanitskaya, E., Andermatt, I., Sadhu, R., and Stoeckli, E. T. (2007). Semaphorin6A acts as a gate keeper between the central and the peripheral nervous system. Neural Dev. 2:28. doi: 10.1186/1749-8104-2-28

Mensch, S., Baraban, M., Almeida, R., Czopka, T., Ausborn, J., El Manira, A., et al. (2015). Synaptic vesicle release regulates myelin sheath number of individual oligodendrocytes in vivo. Nat. Neurosci. 18, 628-630. doi: 10.1038/nn.3991

Monk, K. R., Naylor, S. G., Glenn, T. D., Mercurio, S., Perlin, J. R., Dominguez, C., et al. (2009). A G protein-coupled receptor is essential for Schwann cells to initiate myelination. Science 325, 1402-1405. doi: 10.1126/science.11 73474

Morris, A. D., Lewis, G. M., and Kucenas, S. (2017). Perineurial glial plasticity and the role of TGF- $\beta$ in the development of the blood-nerve barrier. J. Neurosci. 37, 4790-4807. doi: 10.1523/JNEUROSCI.2875-16.2017

Newbern, J., and Birchmeier, C. (2010). Nrg1/ErbB signaling networks in Schwann cell development and myelination. Semin. Cell Dev. Biol. 21, 922-928. doi: 10.1016/j.semcdb.2010.08.008

Niederländer, C., and Lumsden, A. (1996). Late emigrating neural crest cells migrate specifically to the exit points of cranial branchiomotor nerves. Development 122, 2367-2374.

Odenthal, J., and Nüsslein-Volhard, C. (1998). Fork head domain genes in zebrafish. Dev. Genes Evol. 208, 245-258. doi: 10.1007/s004270050179

Perlin, J. R., Lush, M. E., Stephens, W. Z., Piotrowski, T., and Talbot, W. S. (2011). Neuronal neuregulin 1 type III directs Schwann cell migration. Development 138, 4639-4648. doi: 10.1242/dev.068072

Radomska, K. J., and Topilko, P. (2017). Boundary cap cells in development and disease. Curr. Opin. Neurobiol. 47, 209-215. doi: 10.1016/j.conb.2017.11.003

Ravanelli, A. M., and Appel, B. (2015). Motor neurons and oligodendrocytes arise from distinct cell lineages by progenitor recruitment. Genes Dev. 29, 2504-2515. doi: 10.1101/gad.271312.115

Sepp, K. J., Schulte, J., and Auld, V. J. (2001). Peripheral glia direct axon guidance across the CNS/PNS transition zone. Dev. Biol. 238, 47-63. doi: 10.1006/dbio. 2001.0411

Smith, C. J., Johnson, K., Welsh, T. G., Barresi, M. J., and Kucenas, S. (2016). Radial glia inhibit peripheral glial infiltration into the spinal cord at motor exit point transition zones. Glia 64, 1138-1153. doi: 10.1002/glia.22987

Smith, C. J., Morris, A. D., Welsh, T. G., and Kucenas, S. (2014). Contactmediated inhibition between oligodendrocyte progenitor cells and motor exit point glia establishes the spinal cord transition zone. PLoS Biol. 12:e1001961. doi: 10.1371/journal.pbio.1001961

Takada, N., Kucenas, S., and Appel, B. (2010). Sox10 is necessary for oligodendrocyte survival following axon wrapping. Glia 58, 996-1006. doi: 10.1002/glia.20981

Taveggia, C., Zanazzi, G., Petrylak, A., Yano, H., Rosenbluth, J., Einheber, S., et al. (2005). Neuregulin-1 type III determines the ensheathment fate of axons. Neuron 47, 681-694. doi: 10.1016/j.neuron.2005.08.017

Topilko, P., Schneider-Maunoury, S., Levi, G., Baron-Van Evercooren, A., Chennoufi, A. B., Seitanidou, T., et al. (1994). Krox-20 controls myelination in the peripheral nervous system. Nature 371, 796-799. doi: 10.1038/37 $1796 \mathrm{a} 0$ 
Vermeren, M., Maro, G. S., Bron, R., McGonnell, I. M., Charnay, P., Topilko, P., et al. (2003). Integrity of developing spinal motor columns is regulated by neural crest derivatives at motor exit points. Neuron 37, 403-415. doi: 10.1016/s0896-6273(02)01188-1

Voas, M. G., Glenn, T. D., Raphael, A. R., and Talbot, W. S. (2009). Schwann cells inhibit ectopic clustering of axonal sodium channels. J. Neurosci. 29, 14408-14414. doi: 10.1523/JNEUROSCI.0841-09.2009

Welsh, T. G., and Kucenas, S. (2018). Purinergic signaling in oligodendrocyte development and function. J. Neurochem. 145, 6-18. doi: 10.1111/jnc.14315

Wilkinson, D. G., Bhatt, S., Chavrier, P., Bravo, R., and Charnay, P. (1989). Segment-specific expression of a zinc-finger gene in the developing nervous system of the mouse. Nature 337, 461-464. doi: 10.1038/33 $7461 \mathrm{a} 0$

Zalc, B. (2016). The acquisition of myelin: an evolutionary perspective. Brain Res. 1641, 4-10. doi: 10.1016/j.brainres.2015.09.005
Zawadzka, M., Rivers, L. E., Fancy, S. P., Zhao, C., Tripathi, R., Jamen, F., et al. (2010). CNS-resident glial progenitor/stem cells produce Schwann cells as well as oligodendrocytes during repair of CNS demyelination. Cell Stem Cell 6, 578-590. doi: 10.1016/j.stem.2010.04.002

Conflict of Interest Statement: The authors declare that the research was conducted in the absence of any commercial or financial relationships that could be construed as a potential conflict of interest.

Copyright (C) 2018 Fontenas and Kucenas. This is an open-access article distributed under the terms of the Creative Commons Attribution License (CC BY). The use, distribution or reproduction in other forums is permitted, provided the original author(s) and the copyright owner(s) are credited and that the original publication in this journal is cited, in accordance with accepted academic practice. No use, distribution or reproduction is permitted which does not comply with these terms. 